SIR,-Little seems to have been said about the position of the medical assistant if the Government's decisions on the Review Body's report take effect.

A medical assistant must have spent at least two years as a registrar before appointment, and many will have been senior registrars. Yet it is now proposed that he should start at $£ 2,415$ when a second year registrar gets $£ 2,472$, a 3 rd year registrar $£ 2,616$, and a first year senior registrar $£ 2,760$. Not only does a medical assistant give the benefit of more experience and takes less time off for study than the junior doctor but now he is to get substantially less pay for doing it.

If the consultants' pay position demands action how much more does that of the medical assistant-and yet I have not even heard it mentioned.-I am, etc.

\section{Rainhill Hospital,}

E. M. BeLL.

SIR,-Why did the B.M.A. ask doctors to break their contracts before many could consider or even receive the Review Body report and other papers which the B.M.A. sent by second class mail?-I am, etc.,

$$
\begin{gathered}
\text { Chislehurst, } \\
\text { Kent. }
\end{gathered}
$$

JOHN WOODALL.

${ }_{*}^{*}$ The Secretary states: The decision to make a wide distribution of the Review Body's Report and our evidence to it was made some weeks ago, and in readiness for this issue envelopes were prepared and addressed. At that time there was no great urgency attaching to this distribution, and as the cost of first class mail would have

\section{Mothers of Premature Babies}

SIR,-We find ourselves entirely in agreement with the spirit of your leading article (6 June, p. 556). Like you, we believe "that the immediate postpartum period is the most important time for the initial contact between mother and child, as it is in animals." We also believe that it is indeed "natural and normal for a mother in a maternity hospital to have her full term baby not in a nursery but at her bedside. ..." Also, that it would be "natural and normal for a mother of a premature baby to be helped to feel close to him . . . and to maintain contact. ..."We also believe that this applies to all sick newborn babies.

For a number of years one of us (D.H.G.) has been in receipt of a grant from the Oxford Regional Hospital Board to study by means of tape-recorded interviews the feelings and reactions of mothers who have had both the experience of separation with its attendant anxieties and the satisfaction of maintaining contact with their babies from birth. Although it seems unlikely that it will ever be possible to prove that the former is regrettable and harmful and the latter desirable and helpful, preliminary findings support this view.

Because of this and because we agree with you that "there are occasions when one has to make medical decisions on the basis of common sense and what seems natural and normal," we have planned the new special-care baby unit at Wycombe General Hospital so that mothers can be given full involved at least an additional $£ 1,000$ it was decided that second class mail would suffice. The envelopes were therefore overprinted "second class mail."

The Government announced its intentions regarding the Review Body's recommendations on 4 June. The Council and the British Medical Guild met on Saturday 6 June, at which the "sanctions" were decided. By that time it was quite impossible to prepare another $50,000-60,000$ envelopes or to change the postage rate already printed on the envelopes. It was by that time essential to circulate the Government's findings without further delay. The original envelopes were therefore despatched on Monday 8 June. They should have reached doctors on Tuesday or Wednesday-depending upon their address-and more would probably have done so but for the Election postage which had priority. The delay is very much regretted, but the profession is now being kept well informed of recent events.-ED., B.M.f.

SIR,- I am writing on behalf of the medical staff, both junior and senior, of this hospital to offer our thanks and support to Dr. Derek Stevenson and the action committee of the B.M.A for their firm and effective leadership during the recent crisis.

The B.M.A. has often been criticized in the past for indecision, but on this occasion a clear lead has been given and it is vital that the profession give our leaders their complete support.-I am, etc.,

\section{J. R. PAgE.}

Chairman of the Medical Staff General Hospital.

\section{Kettering,}

obstetrical care and yet be with their sick or premature babies from delivery onwards.We are, etc.

\section{H. GaRROW.}

Amersham, Bucks. DERMOD MACCARTHY.

Oxford Regional

Hospital Board.

\section{Narcotic Analgesics}

SIR,-Your expert dealing with narcotic analgesics (30 May, p. 525, and 6 June, p. 587) states that none of the alternatives to morphine eliminates the main disadvantages of this drug. He reminds us that with morphine about $40 \%$ are nauseated and $16 \%$ vomit. He suggests that these complications can usually be successfully treated with antiemetic drugs.

I suggest that the rational approach is to prevent these distressing side effects. This can be done by combining morphine with an antiemetic-preferably cyclizine. In my experience this combination in the form of Cyclimorph (morphine tartrate 10 $\mathrm{mg}$. and cyclizine tartrate $50 \mathrm{mg}$.) is successful in practically eliminating nausea and vomiting. Cyclimorph has no appreciable effect on the blood pressure, and since cyclizine does not belong to the phenothiazine group it does not increase drowsiness. I have now used intravenous Cyclimorph in 60 outpatients for various painful procedures. Only one case of nausea and no instances of vomiting have been recorded in this series. On the wards Cyclimorph has been used for pre-operative medication during the last 18 months. The ward sisters report that there has been a marked reduction in both the incidence and severity of post-operative vomiting.

Though the advantages of morphine and cyclizine have been reported previously ${ }^{1}$ the habit of prescribing morphine without an antiemetic is still widespread. This is a great pity, because it undoubtedly leads to much unnecessary suffering, and in some conditions, such as heart attacks, the vomiting can be a serious hazard.

It is often assumed that pethidine is safer than morphine and that it has fewer side effects. $^{2}$ It is true that pethidine is less likely to be emetic than plain morphine, but pethidine is liable to cause an alarming drop in blood pressure. This is the so-called "pethidine reaction" familiar to most nursing staff. For this reason and also because of its extreme danger in patients taking monoamine oxidase inhibitors I regard pethidine injections as less satisfactory than Cyclimorph.-I am, etc.,

\section{A. W. FOWLER.}

Bridgend General Hospital Bridgend, Glam.

\section{References}

1 Christie, G, et al., British Medical fournal, 1958, 1, 675.
2 Aston, P., British Medical fournal, 1969, 4, 214.

\section{Nifuratel for Trichomonal Vaginitis}

SIR,-Indifferent results from treatment of trichomonal vaginitis with nifuratel as compared with metronidazole have recently been reported in your columns ( 9 May, p. 335, and 30 May, p. 542). Metronidazole has established itself as an effective systemic remedy for trichomonal infection in both sexes, and local vaginal therapy using pessaries must now be regarded as an anachronism.

In 1968 I studied the curative effect of nifuratel tablets (one thrice daily for seven days) given alone without pessaries in young single women infected with $T$. vaginalis. Patients with acute vulvo-vaginitis were selected so that further sexual exposure was unlikely during the treatment week. All 14 cases were re-examined on the last day of treatment or shortly thereafter. One patient was clinically well with negative microscopic and cultural tests on day 12. Another patient was given metronidazole by her own doctor on day 4 and was cured. The remaining 12 patients all showed clinical vaginitis with $T$. vaginalis present on day 7 ( 7 cases), day 9 ( 1 case), day 14 (1 case), day 21 ( 1 case), day 31 ( 1 case), and day 5 ( 1 case).

It seems clear that systemic treatment with nifuratel is ineffective, and that the modest success claimed for the combined treatment depends largely on the use of the nifuratel pessaries. Vaginal therapy alone is known to be followed by relapse in a proportion of women and an effective systemic remedy for the male partner is required to prevent re-infection. I believe that even the combined treatment using nifuratel tablets and pessaries is unsatisfactory in the management of trichomonal infections and should be abandoned.-I am, etc.,

\section{Royal Victoria Hospital, \\ S. M. LAIRD}

